\title{
Kari Igomari Niwara (La casa es de las mujeres) (1981-1995). Las mujeres rarámuri como agentes de cambio ante el desarrollo institucional en la Sierra Tarahumara
}

\author{
Kari Igomari Niwara (The House is for \\ Women) (1981-1995). Rarámuri Women as \\ Agents of Change as Regards Institutional \\ Development in the Sierra Tarahumara
}

\author{
María Isabel Martínez Ramírez \\ (D) 0000-0001-9376-8681 \\ Instituto de Investigaciones Históricas \\ Universidad Nacional Autónoma de México, México \\ isamartinez79@gmail.com
}

Resumen: El objetivo de este artículo es exponer el proceso de constitución de Kari Igomari Niwara en el ejido de San Ignacio de Arareco, municipio de Bocoyna, en la Sierra Tarahumara. Con el propósito de contribuir a la comprensión de la historia reciente de la región, se reconstruye la historia de esta Sociedad de Solidaridad Social a partir de la versión de las mujeres rarámuri con la finalidad de sumar su narrativa a otras. Metodológicamente, se propone someter la etnografía y otros documentos producidos a inicios del siglo xxI a una crítica de fuentes interdisciplinaria. Analíticamente y desde la versión bajo la cual las mujeres rarámuri son agentes de cambio, se describen las transformaciones de los vínculos entre los rarámuri, la Iglesia católica, el Estado mexicano y las ONG en el ámbito de la salud pública (1981-1995), campo de acción en el que se creó Kari Igomari Niwara. 
Palabras clave: mujeres; rarámuri; Sierra Tarahumara; historia reciente; cambio social.

Abstract: The purpose of this article is to describe the constitution of Kari Igomari Niwara in the ejido of San Ignacio de Arareco, in the municipality of Bocoyna in the Sierra Tarahumara. In order to contribute to the understanding of the recent history of the region, the history of this Society of Social Solidarity is reconstructed from the version of the rarámuri women with the aim of adding their narrative to others. Methodologically, ethnography and other documents produced at the beginning of the 21st century are subjected to a critique of interdisciplinary sources. Analytically and based on the version in which rarámuri women are agents of change, the transformations of the links between the rarámuri, the Catholic church, the Mexican State and the NGO in the field of public health (1981-1995) are described. This is the sphere of action in which Kari Igomari Niwara was created.

Key words: women; rarámuri; Sierra Tarahumara; recent history; social change.

Fecha de recepción: 29 de junio de 2017 Fecha de aceptación: 25 de octubre de 2017

\section{INTRODUCCIÓN}

$\mathrm{D}$ urante la última década del siglo xx, en el ejido de San Ignacio de Arareco, ubicado en el municipio de Bocoyna, en la Sierra Tarahumara, Chihuahua, un grupo de mujeres rarámuri constituyó la Sociedad de Solidaridad Social denominada Kari Igomari Niwara (La casa es de las mujeres). ${ }^{1}$

${ }^{1}$ Los rarámuri, mejor conocidos como tarahumaras, son una población de 73856 hablantes reconocidos en 2015 por el Instituto Nacional de Lenguas Indígenas que habitan las cumbres y las barrancas de una porción noroeste de la Sierra Madre Occidental en el estado de Chihuahua. A causa de la violencia provocada por la guerra contra el narcotráfico que sería declarada por el Estado mexicano en la primera década del siglo xxi, desde el 2006 residen con mayor presencia en algunas de las concentraciones urbanas de la Sierra-Cuauhtémoc, Guachochi, Jiménez y Parral-, así como de este estado -Chihuahua, Delicias y Ciudad Juárez-. Entre la estimación de datos de 2010 y 2015 se registró una diferencia de 15647 personas. Instituto Nacional de Lenguas Indígenas (INALI) (2010). Indicadores básicos de la agrupación tarahumara, 2010. Recuperado de http://site.inali.gob.mx/Micrositios/estadis- 
En el invierno de 2014, Martha Villalobos y Todos los Santos Villalobos, fundadoras y colaboradoras activas de la Sociedad de Solidaridad Social, describieron cómo llegaron a administrar algunas tiendas de artesanía y de abarrotes con el fin de fomentar el autoconsumo y la autosustentabilidad comunitaria, cómo fundaron dos escuelas autogestivas -Biniwami Rarámuri Niwára (La enseñanza es de los rarámuri), inscritas en la Secretaría de Educación Pública como preprimaria (08PPB0001S) y como primaria (08PCC0001N)-, y cómo el antecedente fue una reflexión sobre la violencia familiar y de género. ${ }^{2}$

Con la finalidad de indagar la historia de la conformación de Kari Igomari Niwara, revisé las investigaciones académicas de corte etnográfico que ejecutadas durante las dos últimas décadas del siglo pasado y publicadas durante la primera década de esta centuria describieron la constitución de esta Sociedad, así como documentos institucionales y periodísticos relacionados con este tema. Advertí que en esta documentación, la narrativa de algunas mujeres rarámuri -registrada durante los inviernos de 2014, 2015 y el verano de 2016 en tres entrevistas formales y siete informales realizadas en la Ciudad de México y el pueblo de Creel, municipio de Bocoyna- estaba parcial o totalmente ausente, específicamente su papel como agentes de cambio. Por ello, a través de herramientas antropológicas e historiográficas problematicé metodológicamente: a) cómo historizar estos documentos mediante una crítica de fuentes, particularmente las descripciones etnográficas, y b) cómo la perspectiva de las rarámuri podía ser constitutiva de una historia reciente.

Para el primer caso, a la reflexividad que instituyó a la antropología moderna -expresada con mayor énfasis en la posición teórica y política del investigador o de la investigadora, en la crítica explícita de las relaciones de jerarquía entre estos y los sujetos o los colectivos descritos, así como en una preocupación por las técnicas de enunciación y de la escritura-, ${ }^{3}$ sumé una

tica_basica/estadisticas2010/pdf/agrupaciones/tarahumara.pdf. Los motivos de esta baja poblacional podrían articularse con la violencia y el exterminio físico o conceptual a través de las cifras censales.

${ }^{2}$ Con base en mi experiencia de más de una década sobre terreno en la Sierra Tarahumara en distintas comunidades y pueblos rarámuri (entre 2002 y 2016), advierto al lector que el material aquí presentado no puede generalizarse. Caracterizados por la producción de diversidad intraétnica, la comprensión de las relaciones de género, sean violentas o no, requiere de investigaciones regionales y locales detalladas.

${ }_{3}^{3}$ En la escuela inglesa de antropología, los parámetros definidos por el trabajo de campo, la reflexividad y la crítica enunciativa en la escritura marcarían el inicio de la época 
crítica de fuentes para cuestionar las motivaciones que llegaron a velar la versión de estas mujeres. Por ejemplo, los intereses mutuos que estarían involucrados en la información registrada, o bien en las consecuencias del "presente etnográfico"; esto es, la subordinación o la abolición de los contextos sociales, políticos e históricos al presente enunciativo (Faubion, 2016; Ingold, 1996). Para el segundo caso, indagué en qué medida la versión de estas mujeres podía ser una narrativa producida durante la primera década del siglo xxi. Para lograrlo, al igual que otros autores que han explorado desde distintas perspectivas los alcances del vínculo interdisciplinario entre la historia y la etnografía en México (Broda, 1995, 2003; López Caballero, 2017; Martínez González, 2013), vinculé la antropología con la investigación de una historia reciente que, como ha indicado Levin Rojo (2016), buscaría: "tejer constantemente el pasado heredado, inscrito en los documentos - pero también las huellas extra-textuales que este ha dejado- con el presente observado y hacer conciencia de que la investigación histórica, también, precisa de la observación actual sobre el terreno, pues es en el presente donde surgen las preguntas que hacen necesario nuestro viaje en el tiempo" (p. 150).

En este tenor, el objetivo de este artículo es exponer la constitución de Kari Igomari Niwara desde una perspectiva rarámuri que ha partido de la observación sobre el terreno en el presente y bajo la cual las mujeres son agentes de cambio en el ejido de San Ignacio de Arareco entre 1981 y 1995 -periodo que inicia con la organización previa a la conformación de esta Sociedad y que finaliza con sus primeros años de operación en el contexto del naciente complejo ecoturístico Kuri Sinéwi Busuréwami (Apenas estamos despertando). Al colocar a las rarámuri como relatoras de su propio devenir, su versión se sumará a otras fuentes que simultáneamente se convertirán en variantes narrativas de los hechos, multiplicando así las perspectivas analíticas. Como advirtió Hobsbawm (2007, pp. 20-21), la historia para el siglo Xxi no puede ser un intento por establecer la gloria o la tragedia de un grupo específico, ni tampoco podemos aceptarla como una lista retrospectiva de deseos para el presente. La tarea en la actualidad, confirmó este autor, "es desmantelar mitos políticos y morales construidos por las historias nacionales, de grupo o

posmoderna en la antropología con Malinoswki (Strathern, 2013), quien históricamente se distinguiría metodológicamente de manera radical de Frazer, instituyendo una nueva tradición. Sobre una discusión de dichos parámetros durante el siglo xx en esta tradición inglesa véase también Strathern (2014). 
de régimen, viejas o nuevas, que son invenciones o incluso cuentos de hadas propagandísticos".

En este sentido, una de las aportaciones de este artículo consiste en documentar la versión de las mujeres rarámuri, ya que esta problematiza sus relaciones con la Iglesia católica y con el Estado mexicano en el marco del reordenamiento territorial de los ejidos y su uso turístico, así como en su vinculación con diversas organizaciones no gubernamentales (ONG). ${ }^{4}$ Además, como parte del diálogo interdisciplinario propuesto, sugiero que una de las contribuciones de este planteamiento para la práctica antropológica residiría en restituir a la historia reciente de la región algunos elementos fundamentales de la realidad concreta al registrar "historias desde abajo", ya que como advirtió Hobsbawm, en las versiones contenidas en las fuentes oficiales, dicha historia tiende al artificio y ocasionalmente está sustentada o es reproducida en documentos de corte etnográfico. Siguiendo de cerca los planteamientos de Levin Rojo (2016), la historización de la etnografía que ejecutaré implicará "trazar rutas indagatorias a partir del cuestionamiento de los paradigmas de unas disciplinas mediante las evidencias que arroja el manejo de las fuentes y métodos que otras privilegian" (p. 150). Finalmente, el caso que presento contribuye a complejizar, a partir del estudio de la historia reciente, los vínculos entre los pueblos indígenas y el Estado mexicano durante el establecimiento del neoliberalismo político, social y económico en el norte de México.

\section{EL COMPLEJO ECOTURÍSTICO KURI SINÉWI BUSURÉWAMI}

El ejido de San Ignacio de Arareco, municipio de Bocoyna, es conocido por ubicarse aproximadamente a $5 \mathrm{~km}$ del pueblo de Creel. Entre los siglos XVIII

${ }^{4}$ Agradezco los comentarios y las sugerencias de los dictaminadores que permitieron afinar este texto. Particularmente por resaltar que los testimonios presentados son análogos entre sí. Advierto que los testimonios de las mujeres rarámuri presentados a lo largo de este escrito son afines entre sí por dos motivos. Primero, porque el contexto de violencia de la región de Creel condicionó la producción de las entrevistas realizadas entre 2015 y 2016, limitando la inmersión de campo en el ejido de San Ignacio de Arareco a través de la cual probablemente se identificarían procesos de negociación y versiones contrapuestas. Segundo, en la documentación de segunda mano revisada tampoco fueron registradas discordancias entre las versiones de las mujeres; hecho que podría ser un indicio de la producción colectiva del proceso de cambio ocurrido entre 1981 y 1995 que describiré. 
y xix esta región perteneció al rectorado de Nuestra Señora de Guadalupe de Bocoyna, fundada en 1702 por la Compañía de Jesús, y fue una dependencia del municipio de Sisoguichi hasta que en 1886 se integró jurisdiccionalmente a Carichí, decretado municipio a fines de 1911. Como sugieren Farías Martínez y Aranda Gutiérrez (2008, p. 75), es posible que el pueblo se conformara luego de la construcción del templo en 1903 por el padre J. S. Gassó, ya que el documento escrito en 1955 por Ocampo (1966) señala que entre sus acciones: "fundó además varios pueblos nuevos [como] San Ignacio, todos con su templo de piedra y sus límites bien trazados; consiguió que se repararan las casas de Cusaráre, y los de los Bajíos" (p. 90). Durante el reparto agrario, a pesar de ser reconocido inicialmente como un pueblo rarámuri con potencial de restitución y ante la falta de títulos primordiales, San Ignacio de Arareco fue concedido como ejido a 165 campesinos por resolución presidencial el 27 de septiembre de 1928. En 1996, el Programa de Certificación de Derechos Ejidales y Titulación de Solares Urbanos (Procede), declaró que las 20 45728 hectáreas que lo conformaban eran propiedad colectiva de 400 ejidatarios (Trevinzo Nevárez y Abúndez Ramírez, 1996); mientras que el Instituto Nacional de Estadística y Geografía (INEGI) reportó en 2005 un conteo aproximado de 2273 habitantes. Como mostraré, un aspecto relevante de estos ordenamientos es el uso prescriptivo que se ha hecho del territorio, tal como la empresa ecoturística.

Este ejido se constituyó legalmente como el primer complejo ecoturístico y empresa ejidal de la Sierra Tarahumara el 29 de mayo de 1992 bajo la denominación Kuri Sinéwi Busuréwami S. S. S. (Apenas estamos despertando). De acuerdo con Servín Herrera (2008, pp. 136-142), el gobernador en turno, Fernando Baeza Meléndez (1986-1992) mediante el gobierno del estado decretó la expropiación de la Laguna de Arareco ${ }^{5}$ y propuso un plan de trabajo para fortalecer el turismo en el estado de Chihuahua y generar mayores ingresos en la entidad. El 3 de octubre de 1991, 144 ejidatarios recibieron un citatorio que indicaba "debían presentar pruebas y alegatos por haber desocupado el ejido por más de dos años y no haber sembrado la tierra”

${ }^{5}$ La imprecisión del término laguna o lago de Arareco podría derivar de que este cuerpo de agua de aproximadamente 40 hectáreas es una represa artificial que fue construida por Luis Guillermo Verplancken J. S., con el objetivo de dotar de agua a la región, particularmente al pueblo de Creel. Esto permitiría cuestionar en una futura investigación bajo qué términos legales y ontológicos el gobierno del estado de Chihuahua ejecutó la expropiación de la "Laguna de Arareco". 
en un juicio que se celebraría el 15 de octubre. Los días 15 y 16 de octubre de ese mismo año, 400 hombres y mujeres rarámuri del ejido de San Ignacio de Arareco integraron una comitiva de negociación ante el gobernador que precedió a una marcha instalada en la Plaza de Armas, ubicada frente al Palacio de Gobierno en la ciudad de Chihuahua (Pérez Castro Vázquez, 2004, p. 91; Servín Herrera, 2008, p. 136). El mandatario sugirió a la comitiva plantear un proyecto propio que sería aceptado por Baeza Meléndez seis meses después. Los rarámuri de este ejido fueron canalizados al Fondo Nacional de Empresas de Solidaridad (FonAEs), donde recibieron financiamiento mediante un sistema de préstamo para construir una infraestructura básica como casetas de cobro y el mantenimiento de caminos para realizar paseos en vehículos, bicicleta de montaña, a caballo o caminatas guiadas (Anderson, 1994; Pérez Castro Vázquez, 2004, p. 63; Servín Herrera, 2008, pp. 139, 141). Actualmente, estos y otros servicios, como la renta de lanchas en la laguna, renta de cabañas en Segórachi y Batosárachi, zonas para acampar, paseos por cascadas como Rukíraso y Ekarina, y un parque acuático de aguas termales en Recowata, son administrados y gestionados por los rarámuri del ejido (Sariego Rodríguez, sin año).

A diferencia de las versiones registradas en estos y otros documentos, en la experiencia y la narrativa de algunas de las mujeres rarámuri que constituyeron Kari Igomari Niwara, su papel en la defensa de la laguna y, por tanto, en la institución del complejo ecoturístico fue imprescindible, tal como Josefina Ruiz González declararía en 2004:

Eso del proyecto turístico más bien fuimos las mujeres las que lo ganamos, porque nosotras fuimos las que movilizamos a la gente, ni siquiera fueron los hombres, ni las autoridades. Nosotras, todas las promotoras [de salud y de educación], fuimos las que movimos a toda la gente para hacer el proyecto. Nosotras fuimos las que hicimos los talleres. Los hombres no entendían. Entendían más las mujeres, nosotras fuimos las que nos movimos. Si no hubiera sido por nosotras hubiéramos perdido la Laguna de Arareco. ${ }^{6}$

En consecuencia, para algunas de estas mujeres los procesos de autogestión que, en la documentación revisada, podrían traducirse como "desa-

${ }^{6}$ Ruiz González, J. (julio de 2004). Entrevista a Josefina Ruiz González/Entrevistadora Servín Herrera, Lagura de Arareco, Chihuahua (Servín Herrera, 2008, p. 146). 
rrollos institucionales", han sido producto de una experiencia propia, la cual no conllevaría a un aislamiento de las figuras gubernamentales o estatales en el presente, ni en el pasado, tal como lo he argumentado en otro escrito (Martínez, 2017). ${ }^{7}$ Por ejemplo, durante el proceso de la conformación de Kari Igomari Niwara, entre 1981 y 1995, la ausencia del Estado de bienestar se materializó en la presencia de la Iglesia católica como la institución promotora de la salud y de la educación en San Ignacio de Arareco; de forma análoga a como Martínez y Fujigaki (2014) lo documentaron en la región de Norogachi, municipio de Guachochi. Simultáneamente, el Estado postrevolucionario tuvo una fuerte intervención en esta zona, al igual que en el resto de la Sierra Tarahumara, mediante el ordenamiento territorial en ejidos con el objetivo de usarlos prescriptivamente como empresas forestales. En la década de los noventa, la presencia del Estado adquirió una nueva faceta a través del reordenamiento ejecutado por el Procede, los usos turísticos y de explotación minera prescritos, así como con la apertura hacia las ong para intervenir en los campos de la salud y de la educación. En los intersticios de este tejido sin costuras entre el Estado, la Iglesia católica y las ONG, a fines del siglo $\mathrm{xx}$ y principios del xxI, los rarámuri encontraron espacios para crear procesos de autogestión. Por ello, sumado a la importancia de la mediación de las ONG en estos procesos, considero que como afirmaron las mujeres de San Ignacio de Arareco, la experiencia y los intereses rarámuri antecedía a su intervención institucional.

Por este motivo, es necesario describir la versión de las mujeres rarámuri, así como problematizar su ausencia parcial o total como agentes de cambio en otros registros. ${ }^{8}$ Para relatar el surgimiento de Kari Igomari Niwara primero expondré las versiones documentadas, así como sus condiciones de enunciación, para posteriormente, con base en estas fuentes, reconstruir los acontecimientos compartidos por algunas mujeres rarámuri entre 2015 y 2016.

7 Un ejemplo de esto es el término de "promotor" o "promotora", el cual tuvo su origen en la política de "acción integral" del indigenismo en la Sierra Tarahumara (1952-1972) (Sariego Rodríguez, 2015, pp. 98, 271).

${ }^{8}$ Advierto que los registros escritos y los testimonios de estas mujeres están atravesados por una problemática de género que ha sido abordada desde distintos enfoques que describiré a lo largo de este texto. Si bien una de mis preocupaciones teórico metodológicas ha sido que la perspectiva de los rarámuri sea constitutiva de la reflexión, incluyendo su experiencia sobre la violencia familiar y su posicionamiento de género, mi análisis no se enfocará exclusivamente en estos últimos tópicos porque, en un proceso de cambio social más amplio y considerando la perspectiva rarámuri, estos son un elemento fundamental entre otros. 


\section{KARI IGOMARI NIWARA: LAS VERSIONES DOCUMENTADAS Y SUS CONDICIONES DE ENUNCIACIÓN}

De acuerdo con Servín Herrera (2008, pp. 157-158) -antropóloga y activista interesada en la implementación y el mejoramiento de proyectos autosustentables de desarrollo, definidos desde los conceptos y las experiencias de las mujeres en la Sierra Tarahumara, y quien documentó la conformación de Kari Igomari Niwara desde 1986- esta organización se constituyó legalmente en 1994 con alrededor de 200 mujeres como parte del complejo ecoturístico y como una alternativa de desarrollo para las mujeres con el objetivo de generar opciones laborales, tales como las tiendas de artesanías.

Pérez Castro Vázquez (2004, p. 18) -integrante de la asociación civil Alternativas de Capacitación y Desarrollo Comunitario, AlCadeco, A. C., la cual promovió en los ochenta la corporación incipiente de un grupo de promotoras de salud, la constitución de la primera escuela autónoma y la sustentabilidad económica mediante la conformación de tiendas de artesanías y abarrotes entre las mujeres de San Ignacio de Arareco- ${ }^{9}$ indicó que esta Sociedad de Solidaridad Social era una organización de mujeres de distintas comunidades rarámuri que articuló proyectos, servicios y actividades productivas desde la perspectiva de género definida por esta asociación civil. Su objetivo ha sido que las mujeres incidan en:

el proceso de la toma de decisiones de las comunidades mediante el acceso y control de los diversos medios de producción que han ido necesitando, de tal forma en que al ser ellas dueñas de los distintos servicios, poco a poco tengan que participar en los distintos procesos de su pueblo. [En 2003] están legalmente constituidas, son aproximadamente 156 socias, aunque en realidad, alrededor de 60 son las más activas y las que demuestran una participación real, constituyéndose como promotoras de los distintos servicios. Lo anterior

9 Alcadeco, A. C. apoyó y financió desde 1995 hasta 2002 dos proyectos en San Ignacio de Arareco: "Biniwari Rarámuri Niwara" (Izz/Dvv Alemania), Capacitación y perforación de pozos de agua en San Ignacio de Arareko (Demos IAP, México). Además vinculó organizaciones locales con otras ONG estatales, nacionales e internacionales; así Kari Igomari Niwara estuvo articulada al cAmт (Centro de Atención a la Mujer Trabajadora), Milenio Feminista (que aglutinaba varias redes) y CEAAL (Consejo de Educación de Adultos en América Latina) (Pérez Castro Vázquez, 2004, pp. 68-72). 
se debe fundamentalmente a que el analfabetismo y el monolingüismo existente les impide a muchas de las mujeres participar. Actualmente la sociedad cuenta con: un proyecto de salud, tres tiendas de productos básicos, una de artesanías, un transporte público, una granja avícola, una escuela preescolar y primaria y un programa de alfabetización de adultos (Pérez Castro Vázquez, 2004, p. 98).

Alcadeco, A. C. fue una organización no gubernamental sin fines de lucro, ni religiosos o políticos que adquirió personalidad jurídica el 8 de agosto de $1995 .^{10} \mathrm{Su}$ objetivo fue "promover el desarrollo sustentable a través de procesos educativos, productivos y sociales entre la población pobre de México, siendo pionera en la incorporación de la perspectiva de género en proyectos de desarrollo entre la población indígena en Chihuahua”. De acuerdo con Pérez Castro Vázquez (2004, pp. 42, 64), la perspectiva de género de esta asociación civil se cimentó en el concepto de "Mujer en el desarrollo", cuya búsqueda fue incidir y transformar aquello que se consideraba "dañino", tal como se expresó en el siguiente reporte de intervención:

La implementación de un proyecto educativo escolar para niños y niñas indígenas [rarámuri] desde la perspectiva de género cuyo objetivo es el de diseñar una currícula que responda a las necesidades desde la cultura y para la cultura, transformando aquellas costumbres que pueden hacer daño, debido a roles y estereotipos tanto femeninos como masculinos que inhiben su acceso a una mejor calidad de vida y a la continuación de los valores existentes en las siguientes generaciones [cursivas mías].

En 2012, la ficha de registro ante la Organización de las Naciones Unidas para la Educación, la Ciencia y la Cultura (unesco) describía que Kari Igomari Niwara se fundó en 1992 porque:

Al término de la edad reproductiva [las mujeres rarámuri] tienen un promedio de 12 hijos, de los cuales se mueren 6 ó 7 por enfermedades de fácil prevención como la diarrea o infecciones respiratorias. De hecho, la mayor mortalidad infantil se presenta más en las niñas, ya que no reciben el mismo trato

${ }^{10}$ Escritura 3838 del volumen 101, Notario Público 18, ciudad de Chihuahua. Citado en Pérez Castro Vázquez (2004, p. 63). 
que los niños. El 90\% de las mujeres admite ser golpeada cotidianamente. Por otro lado, los recursos que obtiene la madre para la familia son empleados en base a las necesidades de los hombres para la adquisición de aquellos productos que demuestren su hombría (tequila, botas, grabadora, etc.). Aunado a lo anterior, las mujeres son consideradas menores de edad: no pueden salir solas, y no pueden decidir a dónde quieren ir. La mayoría refiere haber sufrido abuso sexual de niñas (el abuso sexual de padres a hijas es una práctica común). En este escenario nació la sociedad Kari Igomari Niwara, Sociedad de Solidaridad Social, para incidir en la transformación y el desarrollo de la comunidad. [...] las mujeres indígenas se organizan para tratar de resolverlos, lo cual impulsa diversos proyectos educativos, productivos y sociales para la satisfacción de las necesidades básicas y estratégicas de las mujeres indígenas del ejido de San Ignacio de Arareko (Frade Rubio, 2012).

Acorde con esta información, en 2013 el Boletín Informativo del Fondo Semillas indicó que esta Sociedad de Solidaridad Social se instituyó en 1992 ante:

la necesidad de combatir la violencia contra las mujeres [...] por iniciativa de nueve promotoras de salud locales que buscaban promover la autonomía económica de las mujeres del ejido con alternativas productivas que no se consideraran "trabajo", pues esa definición generaba conflictos al interior de las familias incrementando la violencia contra las mujeres que a su vez necesitaban urgentemente generar ingresos. Así, se convirtieron en una organización con dos ejes de trabajo, la producción artesanal y la prevención de la violencia de género (Kari Igomari Niwara, 2013).

El Fondo Semillas ofreció talleres de salud y educación entre el 2003 y el 2013, así como becas individuales y colectivas. Apoyada por la Sociedad Mexicana Pro Derechos de la Mujer, A. C., se instauró como organización en 1990 con el objetivo de contribuir al cambio social desde una perspectiva feminista, mediante el fortalecimiento de las organizaciones de mujeres en la reivindicación de sus derechos humanos. De acuerdo con su página web: "Son las propias mujeres organizadas quienes identifican los problemas que enfrentan y proponen soluciones. Fondo Semillas les proporciona recursos económicos, capacitación, acompañamiento y fortalecimiento de sus capacidades, así como acercamiento a otros donantes, redes y alianzas" (Semillas, 2017). 
Finalmente, Salgado Estrada -licenciado en derecho que defendería al ejido en distintos litigios agrarios- registró que la persona moral Kari Igomari Niwara se fundó el miércoles 8 de abril de 1992 por Asamblea Constitutiva celebrada en el poblado de San Ignacio de Arareco. Las socias constitutivas fueron 178 mujeres originarias de este ejido y el objetivo social fue la:

creación y desarrollo de varias tiendas de comercialización de productos artesanales y de autoconsumo en los terrenos del ejido; así como la educación de las socias y sus familias en la práctica de la solidaridad social, la afirmación de valores cívicos y nacionales y en la defensa de la independencia política, cultural y económica del país [...] los puestos directivos quedaron a cargo de Martha Villalobos, Angelina González y Juana Vega, como Presidente, Secretaria y Tesorera, respectivamente. [...] Esta asociación tiene una tienda de artesanías y autoconsumo en el Lago de Arareco, que tiene su razón social (Salgado Estrada, 2007, p. 190).

Pese a sus divergencias, estas versiones comparten algunos elementos. El primero es el marco institucional bajo el cual se producen; es decir, la visión parcialmente definida por los intereses de la organización o de la práctica institucional a la que el autor o autora se adscribe. Por ejemplo, Salgado Estrada (2007) enunció que uno de los "objetivos sociales" de esta Sociedad era "la afirmación de valores cívicos y nacionales y la defensa de la independencia política, cultural y económica del país" (p. 190), posiblemente haciendo referencia al acta constitutiva sin citarla o bien a un lenguaje jurídico. Para Servín Herrera (2008, pp. 157-158), quien estaba interesada en conceptos locales de desarrollo, esta Sociedad era parte del proyecto ecoturístico y su meta fue el desarrollo de opciones laborales propias. Para Pérez Castro Vázquez (2004, p. 18), miembro activo de Alcadeco, A. C., los objetivos radicaron en participar en la toma de decisiones, el acceso y el control de los medios de producción, así como en la apropiación de los medios de servicios bajo la perspectiva de género definida por esta organización. Finalmente, para Frade Rubio (2012), quien inscribió esta Sociedad de Solidaridad Social ante la UNESCO en 2012 y para el Fondo Semillas en 2013, además de la búsqueda por la autonomía económica, el motivo principal de su conformación consistió en detener y revertir las consecuencias de la violencia familiar y de género. Por tanto, en estos documentos hay una tensión discursiva entre un proyecto social, turístico y económico y otro fundamentado en una reflexión 
sobre la violencia familiar y de género, dirigido al desarrollo de la autonomía económica, la autogestión de la salud y la educación comunitaria.

Aunado a las condiciones institucionales de la producción enunciativa que he destacado, el segundo elemento compartido es que cada una de estas versiones subordina el proceso histórico que describe a una enunciación enclavada en un "presente", sea o no etnográfico. Por dar un ejemplo, Pérez Castro Vázquez (2014, p. 18) destacó el papel de Alcadeco, A. C., en el diseño del proyecto del complejo ecoturístico en 1991, así como en la evaluación y en la promoción de salud que iniciaría en 1981 en el ejido de San Ignacio de Arareco; pese a que él mismo describió que esta asociación civil se instituyó en 1995 (Pérez Castro Vázquez, 2014, p. 63). El caso de Semillas A. C. (2017) es similar, ya que la narrativa sobre la violencia de género, intensificada desde inicios del siglo xxI, eclipsa la importancia del trabajo de las mujeres rarámuri en este ejido desde la década de los ochenta; mismo que sería su antecedente organizativo.

Por último, cada una de estas versiones expresaría las relaciones y los intereses que algunas de las rarámuri integrantes de Kari Igomara Niwara han mantenido con los autores o autoras de estas fuentes. Este sería el caso de la documentación de Servín Herrera (2008), en la cual a través de las entrevistas, como la citada arriba, se enfatiza el papel de las mujeres en la constitución del complejo ecoturístico. O bien, en las entrevistas que durante la segunda década del siglo xxi algunas de las integrantes de esta Sociedad de Solidaridad Social ofrecieron a Semillas, A. C. (Fondo Semillas, 2010, 2013), y a la prensa nacional (Rodríguez, 2004), subrayando la importancia del proceso de autogestión de las mujeres. Aquí ofrezco algunos ejemplos:

La importancia de estar yo aquí en la organización, de trabajar, pues es de buscar el desarrollo de la mujer; capacitarnos en nuestros derechos, primero conocerlos y luego ya ejercerlos nosotras mismas y luego enséñaselos más bien a nuestros niños. Para nosotras es muy importante enseñarle a nuestros niños a nuestras niñas sobre su igualdad (Fondo Semillas, 2010).

"Primero me di cuenta de que podía aprender, después que conocí mis derechos, decidí separarme de mi esposo, porque me maltrataba mucho", comparte Maribel. "Vi que podía tener mi propio trabajo y dinero y eso me hacía vivir tranquila con mis hijos. Hace falta seguir trabajando con las mujeres 
aquí, porque como yo, hay más mujeres que pueden darse cuenta que sí pueden vivir tranquilas" (Kari Igomari Niwara, 2013).

En San Ignacio de Arareco (cerca de Creel) un grupo de mujeres inició un movimiento desde 1995: Kari Igomari Niwara "para ser más libres y poder andar solas, sin que ellos anden atrás de nosotras, ni nosotras atrás de ellos; para tener fuerza de organización, para que no nos ganen los machos de esta comunidad. Ahora ya no nos golpean, ya se les exige respeto y explicaciones. Antes no ganábamos dinero las mujeres, ahora vendemos nuestras propias artesanías, algunas ya tienen sus tierras, aunque no nos reconozcan como sucesoras; en la costumbre rarámuri si heredábamos las mujeres" (Rodríguez, 2004).

Recapitulando, al problematizar la historicidad de la etnografía se han evidenciado algunas de las consecuencias del presente enunciativo sobre el recuento de los hechos y se han destacado con mayor nitidez los intereses de los agentes involucrados en la producción de los documentos. Además, como es sabido, todo material nuevo genera otras versiones de la historia. Por ello, al someter algunos documentos producidos durante los siglos Xx y xxI a esta crítica de fuentes que integra la reflexividad antropológica, tales como los generados por las ONG y otras instituciones gubernamentales, se incrementa su potencial para utilizarlos en la elaboración de una historia reciente capaz de dialogar y reconocer en su complejidad la perspectiva de los rarámuri, particularmente como agentes de cambio. ${ }^{11}$

Este sería el caso de las declaraciones de las mujeres rarámuri antes expuestas, las cuales fueron registradas en videos, páginas web y en periódicos electrónicos. En estos fragmentos de entrevista se destacan términos como "derechos", "maltrato", "golpes", "respeto", "trabajo", "igualdad" y "libertad" que, pese a enunciarse de forma desarticulada por el formato de cada soporte, expresarían los intereses de estas mujeres. Primero porque algunas de ellas explícitamente promueven la difusión de sus actividades colectivas, es-

${ }^{11}$ Los datos producidos por las ONG, en tesis, libros o documentos electrónicos (videos, páginas web, plataformas de redes sociales); así como los generados por las instituciones gubernamentales en páginas web, artículos y otros electrónicos requieren un tratamiento metodológico propio por sus condiciones de producción y su inestabilidad material. Metodológicamente esto ha sido un reto para investigar datos de la relación entre los pueblos indígenas y el Estado mexicano durante las últimas dos décadas del siglo xx y las primeras del xxI, es decir, durante la instauración práctica del estado neoliberal en la Sierra Tarahumara. 
pecíficamente las de escolarización, con el fin de recabar fondos económicos para dar continuidad a sus proyectos. Luego, porque para ellas es relevante que su experiencia sobre la violencia familiar y de género sea divulgada con el fin de expandir su injerencia sobre este campo de acción a nivel local. Un ejemplo de esto es lo que Todos los Santos Villalobos me comentó en julio de 2014:

Por invitación del Padre Javier "Pato" Ávila de cosyddhac, A. C., a veces he sido traductora en el ministerio público de Bocoyna, en casos de violencia familiar para las mujeres del ejido de San Ignacio y de otros ejidos. Ahora hay muchas denuncias. Por ejemplo, en casos no graves. Como por ejemplo, un hombre tiene otra mujer, y eso causa peleas, y eso pueden resolverlo con sus gobernadores rarámuri. ${ }^{12}$ Pero a veces, la mujer va a denunciarlo y los gobernadores rarámuri [por lo general varones] no le hacen caso. Luego, cuando hay golpes, se hace una denuncia y la mujer tiene que ir a ministerio público. [Le pregunto si los casos se llegan a solucionar]. Sí, ha habido muchas detenciones. Y entonces, los hombres entienden. Creo que entienden que no es tan fácil hacerlo y que no pueden volver hacerlo. Sin embargo, sería mucho mejor tener una mujer rarámuri trabajando en el municipio..$^{13}$

En lo que resta del artículo utilizaré algunos documentos sometidos a este tratamiento de fuentes interdisciplinarias con el objeto de emplearlos como un recurso para reconstruir, desde la perspectiva de las mujeres rarámuri, una historia reciente de Kari Igomari Niwara.

${ }^{12}$ Los gobernadores rarámuri o siríame son autoridades elegidas y reconocidas por la población que se concentra en los pueblos, es decir, en los espacios territoriales donde tendencialmente se ubican una Iglesia, un centro médico y una escuela. La función más importante de dichas autoridades es ofrecer un sermón (nawesári) en cada reunión colectiva, generalmente los domingos, para compartir por medio de la palabra "la costumbre" que literalmente se traduce como el camino de los antepasados (anayáwari boé). Además son los encargados de dirigir los juicios de carácter colectivo y dirimir los conflictos territoriales y morales en su jurisdicción, y ser el vínculo principal entre las autoridades no rarámuri y la gente que lo eligió.

${ }^{13}$ Villalobos, T. S. (25 de julio de 2016). Entrevista con Todos los Santos Villalobos/ Entrevistadora María Isabel Martínez Ramírez, Creel, Chihuahua. 


\section{KARI IGOMARI NIWARA: RECONSTRUCCIÓN DE LA VERSIÓN DE LAS MUJERES RARÁMURI}

Le pregunto a Martha Villalobos y a Todos los Santos Villalobos por el litigio de la laguna de Arareco en la década de los noventa del siglo pasado, Martha recuerda y afirma: "cuando el gobierno nos avisó; en ese tiempo vivía gente cerca del lago, pero no fueron desplazados porque apenas recibieron la notificación se fueron a marchar y resolvieron todo el asunto”. ${ }^{14}$ Para corroborar si en ese momento constituyeron Kari Igomara Niwara, cuestionó “¿Fue entonces cuando hicieron la cooperativa?" Todos los Santos responde: "desde antes ya éramos promotoras de salud. Así fue que comenzamos la organización". ${ }^{15}$

De acuerdo con los registros de Pérez Castro Vázquez (2004, pp. 99103) y Servín Herrera (2008, pp. 111-136), desde 1981 algunas mujeres rarámuri del ejido de San Ignacio de Arareco participaron como voluntarias, iniciando un programa de capacitación y conformación de promotoras de salud cuya labor consistió en controlar la desnutrición infantil. A la par, participaron en programas de alfabetización. Como indiqué, para ellas, esto conformaría la base organizativa para la defensa del territorio en 1991. De forma similar, y en contrapunto con las versiones registradas, donde la intervención de los actores institucionales o de los asesores de las ong es descrita como el factor fundamental para el nacimiento y el desarrollo de esta Sociedad de Solidad Social, para estas mujeres la violencia familiar y de género que antecedía a estos vínculos fue el motor de sus acciones. Mas aún, una de las premisas conceptuales y pragmáticas podría radicar en los fundamentos de su sociabilidad; bajo los cuales todas las relaciones requieren de cuidado. ${ }^{16}$ Traducido al pensamiento y a la práctica rarámuri, este "tener cuidado" o "cuidar del otro" involucraría la observación del caminar (iyéema, iyétoma y yema); misma que sería la base para establecer y dar continuidad a cualquier vínculo por medio de las acciones, el pensamiento y la palabra. Idealmente

${ }^{14}$ Villalobos, M. (25 de julio de 2016). Entrevista con Martha Villalobos/ Entrevistadora María Isabel Martínez Ramírez, Creel, Chihuahua.

${ }^{15}$ Villalobos, T. S. (25 de julio de 2016). Entrevista con Todos los Santos Villalobos/ Entrevistadora María Isabel Martínez Ramírez, Creel, Chihuahua.

${ }^{16}$ Esta idea fue el resultado del diálogo mantenido con Alejandro Fujigaki Lares, a quien agradezco la lectura del manuscrito previo, los comentarios y las sugerencias que robustecieron mi propuesta inicial. 
esto evitaría equívocos que conducirían al conflicto e inevitablemente a la enfermedad colectiva que también deberá resolverse conjuntamente. Así, los esfuerzos y el trabajo invertidos en evitar el conflicto son tantos como los empleados para su resolución (Martínez, 2012, pp. 291, 292, 297). Por ello, sugiero que para estas mujeres la posibilidad de modificar relaciones conflictivas con base en el cuidado colectivo y relacional fue una premisa que facilitó el vínculo con las ONG y con otras intervenciones institucionales, estimulando la convergencia de intereses.

Aún así en el relato de Servín Herrera (2008, pp. 113-115) "las primeras experiencias del desarrollo" fueron gestionadas por Luis G. Verplancken, J. S., quien durante 40 años de trabajo edificó la escuela albergue para niños indígenas en Gonogochi, ejido de San Ignacio de Arareco, donde se impartía educación primaria. ${ }^{17}$ Él era el responsable de su funcionamiento, sostenimiento y administración a través de donativos personales y de fundaciones nacionales y extranjeras. Siguiendo a la autora, desde 1981 en este albergue de Gonogochi se promovieron proyectos piloto de desarrollo agrícola, hortícola y ganaderos con la finalidad que desde temprana edad los niños rarámuri conocieran y ejercitaran habilidades para este tipo de industrias, fortaleciendo simultáneamente su cultura, con la finalidad de que llegasen a ser maestros. Luego de cuatro años estos proyectos terminaron sin tener continuidad y fueron olvidados.

En concordancia con esta versión, Farías Martínez y Aranda Gutiérrez (2008, pp. 5, 9, 21) señalaron que el Programa de Servicio Social y Desarrollo Rural que sostenía la Facultad de Zootecnia, hoy Facultad de Zootecnia y Ecología de la Universidad Autónoma de Chihuahua (UACH), vinculó brigadas semestrales de estudiantes que realizaban servicio social durante los fines de semana en San Ignacio de Arareco impartiendo cursos de capacitación, asesoría y gestoría, e implementando los proyectos señalados en la guía de servicio social hasta la década de los noventa. Estos autores destacaron que Gonogochi era un internado indígena manejado por voluntarios jesuitas, quienes desarrollaban un modelo educativo innovador capaz de integrar "la

${ }^{17}$ También fundaría la escuela albergue de Basíware en el ejido de Rejogochi, la clínica Santa Teresita en el pueblo de Creel para mestizos y rarámuri; la tienda de artesanías para auxiliar los gastos en las obras de beneficencia de los rarámuri, e instalaría pozos de agua en ranchos y rancherías rarámuri (Servín Herrera, 2008, p. 111). 
autosuficiencia y la equidad de género"; además de alfabetizar a adultos (Farías Martínez y Aranda Gutiérrez, 2008, p. 19).

En la versión que ofrece Pérez Castro Vázquez (2004, p. 86), el proceso de organización de las fundadoras de Kari Igomari Niwara inició entre septiembre de 1984 y agosto de 1985, cuando Frade Rubio elaboró un diagnóstico inicial de la población infantil menor de cinco años. Su muestra estuvo conformada por 100 mujeres y por 147 infantes menores de cinco años. La mortalidad infantil en ese momento era de $65 \%$ de la muestra, es decir, de cada diez hijos morían 6.5 antes de cumplir cinco años durante su segundo año de vida. La primera causa de muerte era la diarrea (41\%) y la segunda las infecciones respiratorias agudas (34\%). Sobre la desnutrición, el $42.85 \%$ de los infantes se encontraba en un estado normal, el 29.9\% en desnutrición y el $11.6 \%$ en segundo o tercer grado de desnutrición. De acuerdo con Pérez Castro Vázquez (2004) para este momento no existían "registros convencionales" (p. 86) o institucionales. Por tanto, estos datos (o su ausencia) serían una expresión del vínculo que el Estado mexicano mantenía con los rarámuri de San Ignacio de Arareco y posiblemente con los habitantes de la región que, cabe recordar, se ubica aproximadamente a $5 \mathrm{~km}$ de Creel, uno de los centros comerciales más importantes de la zona desde la fundación de la Estación del Ferrocarril en 1907.

Luego de la presentación de este balance en materia de salud, Pérez Castro Vázquez cambia su forma narrativa y coloca a Alcadeco, A. C. como el agente de intervención. Por ejemplo, describe cómo: "Lo anterior nos llevó a realizar un estudio de campo en el que se definió exactamente, cuáles eran las causas de la desnutrición imperante" (Pérez Castro Vázquez, 2004, p. 87 [el subrayado es mío]). Como señalé, estas fórmulas narrativas resultan anacrónicas y se sujetan a un presente enunciativo, velando el proceso histórico y social en el que se ubican. Posiblemente, sólo Frade Rubio y él fueron responsables de "pesar y medir a los niños mensualmente" (Pérez Castro Vázquez, 2004 , p. 87) y de promover reuniones informativas sobre prevención de la desnutrición infantil; ya que como apunta Salgado Estrada (2008, pp. 96-97, 190-193, 197), estos asesores llegaron a San Ignacio de Arareco por invitación de Luis G. Verplancken S. J., y participaron en cosydDAHC, A. C., antes de conformar AlCADECo, A. C., en 1995. Estos anacronismos podrían ser indicios de la transformación de los vínculos entre la Iglesia católica, el Estado mexicano, las oNG y los rarámuri de San Ignacio de Arareco hacia finales del siglo xx e inicios del xxi en el ámbito de la salud pública; el cual sugiero llegó 
a ser un campo de convergencia -de proyectos de desarrollo económico, de género y de alfabetización en la región-y por tanto de disputa.

Siguiendo la narrativa de Pérez Castro Vázquez (2004, pp. 89-90), luego de seis años de trabajo, es decir, en 1990, la desnutrición disminuyó del 57.78 a 40\%, desapareciendo el 3er grado. La morbilidad también disminuyó a $31.80 \%$ en diarreas y a $39.64 \%$ en enfermedades respiratorias. En este proceso, en 1988, algunos hombres rarámuri solicitaron capacitación en el área de salud y se convirtieron en promotores dentales. Así fue como en San Ignacio de Arareco se construyó un centro de salud y un dispensario médico, cuya principal limitación fue el financiamiento para la compra de medicamentos. Sin embargo, de acuerdo con este autor, la desnutrición permanecía como un problema:

por lo que las promotoras [analizaron] con detenimiento las familias en las cuáles aparecía dicha enfermedad [y] llegaron a la conclusión de que el problema fundamental [era] la barrera "económica". En su mayoría, estas mujeres eran artesanas, $y$ discutieron el papel de la intermediación en la venta; ya que esto disminuía los ingresos. Después de un año de reflexión, instalarían la primera tienda que daría origen a Kari Igomari Niwara.

Sin negar los hechos descritos hasta este momento, para las mujeres rarámuri con las que conversé y aquellas con las que Servín Herrera tuvo interlocución en 2004, el antecedente para aceptar la intervención de estos agentes fueron los contextos de violencia familiar y de género que ellas padecían y que, afirmaban, las mujeres de generaciones anteriores también habían sufrido. Martha Villalobos comentó, confirmando algunos de los datos expuestos hasta este momento, que en la década de los ochenta: "ellas ya eran promotoras de salud y que fue así que comenzaron su organización. Iniciamos como una organización que se encargaba de medir y pesar niños porque había muchos con desnutrición”. ${ }^{18}$ Todos los Santos Villalobos agregó: "y notamos que los niños que tenían más desnutrición eran de mujeres que casi no hablaban español y por eso comenzamos con educación para adultos". Pregunté cuáles eran las causas de la desnutrición. Todos los Santos dijo:

${ }_{18}$ Villalobos, M. (25 de julio de 2016). Entrevista con Martha Villalobos/Entrevistadora María Isabel Martínez Ramírez, Creel, Chihuahua. 
es que había mucho alcoholismo y les pegaban mucho a las mujeres. Entonces, el proyecto se vinculó con la promoción de salud, con educación para adultos, para formar en derechos contra la violencia familiar y el alcoholismo. Y así nos convertimos en las malas de la comunidad porque en ese tiempo era muy difícil hablar de esos temas, de planificación familiar, de cómo controlar no tener muchos hijos. ${ }^{19}$

En las entrevistas de 2004 documentadas por Servín Herrera (2008), las mujeres rarámuri reconocían el trabajo de los asesores de las ONG sin velar su propio papel como agentes de cambio; hecho que contrasta con la discursividad de las versiones revisadas hasta este momento en las que se excluyó dicha agencia femenina. Dado el efecto de ocultamiento, considero indispensable cuestionar los motivos que dificultan reconocer, aun cuando se cita textualmente las palabras de las rarámuri, su experiencia e intereses en un proceso de cambio. Sumado a esto, pese a que en los testimonios recopilados por Servín Herrera la inequidad de género está presente, la violencia familiar como motor del cambio social aún no es explícita como en el siguiente caso:

La asesora lo inició. Bueno, más bien en un principio ella hacía visitas para curar gente en la salud. Entonces se inició todo junto: la alfabetización y la promoción de salud. [Interrumpe la entrevista su esposa Luisa que es alfabetizadora y promotora de salud y dice:]. Yo me acuerdo que yo estaba ahí y fui de las que empezó a enseñar a las mujeres grandes a que se alfabetizaran. Yo no terminé la primaria, yo salí de tercer año, pero pos ella me enseñó algo y me dijo que yo alfabetizara a otros y trabajara en la promoción de salud. ${ }^{20}$

Sobre este tema Josefina Ruiz en 2005 declaró que:

Mi esposo me golpeó durante casi 15 años. Los hombres cuando nos golpean nos dan en la cara, y también en todo el cuerpo, pero cuando él me golpeaba yo escondía la cara porque es donde más se ve que la golpean a uno, y luego,

${ }^{19}$ Villalobos, T. S. (25 de julio de 2016). Entrevista con Todos los Santos Villalobos/ Entrevistadora María Isabel Martínez Ramírez, Creel, Chihuahua.

${ }^{20}$ Sebastián Pancho, I. y Batista, M. L. (julio de 2004). Entrevista a Isidro Sebastián Pancho y María Luisa Batista/Entrevistadora Servín Herrera, San Ignacio de Arareco, Chihuahua. En Servín Herrera (2008, p. 146). 
luego la gente se da cuenta. Yo no me defendía porque yo pensaba que era así la vida de uno como mujer, que se tenía que aguantar, porque así fue la de mi mamá. Ahora mi esposo ya no me pega. Desde que yo aprendí a saber cuáles eran mis derechos como mujer pos empecé a hablar con él, aunque me costó mucho convencerlo. Ahora sí discutimos cuando él anda borracho, o también cuando anda bueno y sano, pero ya no me golpea. Poco a poco fue entendiendo. Pero todavía hay muchas mujeres que las golpean cuando ellos están borrachos. ${ }^{21}$

Por una parte, esto podría ser una muestra de cómo la narrativa sobre la violencia familiar y de género, como motor del cambio y fundamentada en una experiencia colectiva de las mujeres, se conformó y adquirió intensidad a inicios del siglo XXI; lo cual confirmaría que la vinculación con las ong también se construyó sobre la sociabilidad rarámuri, cuyas premisas involucran transformar los vínculos que "no cuidan colectivamente" el camino de todos. Por otra parte, también es un indicio de que incluso en los documentos de corte etnográfico que fueron producidos manifiestamente bajo una perspectiva de género, dicha narrativa ha sido velada parcial o totalmente. Sugiero que uno de los motivos es que discursivamente, las causas del cambio social se adjudican de forma unilateral a las instituciones gubernamentales y a los organismos no gubernamentales, así como a los programas de desarrollo que estos promueven. De tal manera que las experiencias y los intereses de las mujeres, incluyendo los contextos de violencia que antecedían a la participación de las ONG, quedan reducidos a ser consecuencias de la intervención institucional.

Desde la versión de las mujeres rarámuri, en 1990 ellas consideraron que una de las estrategias para erradicar de fondo la desnutrición sería compartir su proceso de alfabetización; ya que podrían "enseñar y contar a otros hombres y mujeres la importancia de reconocer los derechos y la libertad de las mujeres". ${ }^{22}$ Pero, ipor qué las mujeres decidieron participar en la resolución de un problema de salud a través de la alfabetización? Es posible explicar esta decisión desde la conceptualización y la pragmática de la sociabilidad

${ }^{21}$ Ruiz, J. (julio de 2005). Entrevista a Josefina Ruiz/Entrevistadora Servín Herrera, Laguna de Arareco, Chihuahua. En Servín Herrera (2008, pp. 90-91).

${ }^{22}$ Villalobos, M. y Villalobos, T. S. (26 de julio de 2016). Entrevista a Martha Villalobos y a Todos los Santos Villalobos/Entrevistadora María Isabel Martínez Ramírez, Creel, Chihuahua. 
rarámuri por dos motivos. Primero, porque al igual que el kórima o el sistema de intercambio y de distribución articulado en el principio de "quien tiene más (comida, conocimiento y relaciones) otorga a quien tiene menos", ${ }^{23}$ la alfabetización fue distribuida en redes que seguían esta lógica. Segundo, porque en esta sociabilidad los problemas y su resolución son relacionales. En otras palabras, la desnutrición sólo se resolvería atendiendo la violencia familiar o de género -recordemos que la enfermedad colectiva suele ser producto de conflictos sociales-, así como la violencia familiar o de género sólo se solucionaría con la distribución y el intercambio de conocimiento y de alimento -esto es, con la conformación y la consolidación de redes sociales para ejecutar dicha distribución e intercambio. En síntesis, la decisión para solventar un problema de salud consistió en conformar redes para distribuir e intercambiar conocimiento, es decir, en crear "caminos colectivos" para el "cuidado mutuo".

Así, de acuerdo con Martha Villalobos y Todos los Santos Villalobos, a la par de la alfabetización iniciaron un programa llamado Hablando de Mujer a Mujer para ofrecer charlas y formación de violencia familiar. ${ }^{24} \mathrm{Y}$ pese a recibir agresiones por parte de algunos hombres del ejido mediante la burla, uno de los efectos fue integrar en este proceso a hombres y mujeres. En 2004 Josefina Cruz González y Crucita Ramírez Juárez describieron esta experiencia de la siguiente manera:

La primera vez que iniciamos fue con alfabetización y salud al mismo tiempo. Porque de ahí, de trabajar capacitando a promotoras de salud, se vio la necesidad de que muchas de nosotras y de las demás mujeres de San Ignacio no sabían leer y escribir. Y como ellas, al aprender a leer y escribir, podían cuidar mejor a sus hijos, entonces de ahí salió la necesidad de enseñarles a

${ }^{23}$ El kórima ha sido una práctica constitutiva de la forma de vida rarámuri y, por tal motivo, ha sido documentada en todas las etnografías y reportes de viaje realizados en la Sierra Tarahumara. Remito al lector a uno de los trabajos etnográficos más recientes, documentado a partir de un estudio de caso minucioso en la ciudad de Chihuahua (Morales Muñoz, 2014). En este último contexto, el kórima adquirió matices que Morales Muñoz analizó (pp. 152-158, 180-189). En el contexto serrano, esta práctica del compartir se ha fundamentado en la cortesía del que dona y no en la carencia del que recibe; garantizando que en el futuro este donador reciba la cortesía y el cuidado de otras personas.

${ }^{24}$ Villalobos, M. y Villalobos, T. S. (26 de julio de 2016). Entrevista a Martha Villalobos y a Todos los Santos Villalobos/Entrevistadora María Isabel Martínez Ramírez, Creel, Chihuahua. 
leer y escribir [...] Después que aprendimos nosotras, empezamos a alfabetizar a otras mujeres, y algunas de esas mujeres alfabetizaban a otras. Era como una cadena para que las que se alfabetizaban enseñaran a otras a aprender a leer y a escribir. ${ }^{25}$

Al principio lo hacíamos yendo casa por casa y después ya los juntábamos en un lugar. Bueno las demás alfabetizadoras se me hace que sí iban por las casas. Yo sí los juntaba aquí en mi casa porque yo tenía muchas gentes que querían aprender y no me daba abasto para todos. Entonces ya nomás los esperaba en mi casa. Aquí los juntaba y aquí venían. Venía todo el día: unos venían temprano y otros más tarde. Los que iban llegando los ponía a estudiar. ${ }^{26}$

El fortalecimiento para la promoción de la salud y la alfabetización para adultos fue apoyado por los jesuitas durante catorce años (1981-1995), quienes de acuerdo con Crucita Ramírez Juárez otorgaban becas de 400 pesos. ${ }^{27}$ A partir de 1995, algunas ong como Alcadeco, A. C., y Semillas, A. C., a través de donativos financiarían estos y otros proyectos, hecho que sugiero se manifestaría en algunos de los conflictos en los que estos y otros actores participaron durante las siguientes décadas en el ejido de San Ignacio de Arareco. ${ }^{28}$ Como advertí, la administración y la gestión de la salud -así como de la educación- llegaron a ser un campo de disputa entre la Iglesia católica, el Estado mexicano, las oNG y los rarámuri durante lo que va de este siglo; lo cual expresaría un proceso de cambio en una escala más amplia. Si durante casi todo el siglo xx la salud y la educación serían dos bastiones

${ }^{25}$ Cruz González, J. (julio de 2004). Entrevista a Josefina Cruz González/ Entrevistadora Servín Herrera, San Ignacio de Arareco, Chihuahua. En Servín Herrera (2008, p. 117).

${ }^{26}$ Ramírez, C. (julio de 2004). Entrevista a Crucita Ramírez/Entrevistadora Servín Herrera, Rukusárare, Chihuahua. En Servín Herrera (2008, p. 118).

${ }^{27}$ Ramírez, C. (julio de 2004). Entrevista a Crucita Ramírez/Entrevistadora Servín Herrera, Rukusárare, Chihuahua. En Servín Herrera (2008, p. 120).

${ }^{28}$ Uno de los conflictos más costosos que involucró a diversos agentes fue la disputa por la posesión, administración y gestión de la escuela de Gonogochi. Iniciaría en 1995 y los actores que participaron fueron Luis G. Verplancken J. S, y los ejidatarios de San Ignacio de Arareco. Después de una serie de Asambleas ejidales y un juicio de posesión, el edificio y la gestión educativa regresó a manos de los rarámuri en ese mismo año. En 1999, los ejidatarios denunciaron, en un juicio agrario, a Kari Igomari Niwara por ocupar sin permiso la escuela de Gonogochi. Después de una serie de litigios, este juicio finaliza en 2005 a favor de los ejidatarios. Cabe resaltar que agentes de las ONG tuvieron injerencia y presencia en los litigios (Salgado Estrada, 2007, pp. 190-202). 
privilegiados para la articulación de los rarámuri con la Iglesia católica y el Estado mexicano, entre la última década del siglo xx y las primeras del siglo XXI, estos dos ámbitos fueron un campo de convergencia y de contienda en el que participaron nuevos actores como las ONG y los mismos rarámuri. Un ejemplo de esto es cómo, de acuerdo con Martha Villalobos y Todos los Santos Villalobos, el grupo de promotoras rarámuri y la clínica de salud autogestiva de San Ignacio de Arareco en el que trabajaron durante quince años, gradualmente dejarían de funcionar por la introducción del Programa de Ampliación de Cobertura (PAC). ${ }^{29}$

Desde su perspectiva y narrativa "el gobierno les quitó su trabajo de promotoras y metió otras personas, también rarámuri, pero sin formación. Y tampoco daban formación. Nos habían hecho a un lado". En este sentido, además de los conflictos internos que generó la implementación del PAC, el problema radicó en que las necesidades de salud pública no serían cubiertas en su totalidad por falta de capacitación y de conocimiento de las condiciones clínicas de la región. De acuerdo con estas mujeres, esto se observaría en los nuevos problemas de salud provocados por "los cambios de alimentación; otra vez hay mucha desnutrición, porque los niños comen cosas de la tienda, porque las mujeres salen a trabajar y ya no tienen lo que producían antes para alimentarse". ${ }^{30}$

Los antecedentes del PAC se remontan hacia 1970 con el Programa de Extensión de Cobertura en áreas rurales. No obstante, tal como el diagnóstico descrito por Pérez Castro Vázquez demuestra, hasta 1981 en San Ignacio de Arareco, este y otros programas subsecuentes estaban ausentes en la región. De tal manera que el PAC sólo se implementó cuando las mujeres rarámuri de este ejido lograron concretar un proceso de autogestión de la salud pública local. Por tal motivo, en su experiencia, los programas de salud del "Gobierno" -tal como denominan a las políticas públicas dirigidas por la

${ }^{29}$ Estrategia y programa de la Secretaría de Salud, el Programa de Ampliación de Cobertura (PAC) que tiene como objetivo ampliar la cobertura y atender a la población con nulo o limitado acceso a los servicios básicos de salud y para hacer frente a los retos en materia de salud pública, en particular de la población más desprotegida de 18 entidades federativas del país; a este se sumó el Componente de Salud del Programa Progresa (después Oportunidades y hoy Prospera) y el Programa Caravanas de la Salud. Diario Oficial de la Federación, 28 de diciembre de 2013. Secretaría de Gobernación. Recuperado de http://www.dof.gob.mx/ nota_detalle.php?codigo $=5328363 \&$ fecha $=28 / 12 / 2013$

${ }^{30}$ Villalobos, T. S. (25 de julio de 2016). Entrevista con Todos los Santos Villalobos/ Entrevistadora María Isabel Martínez Ramírez, Creel, Chihuahua. 
federación o el gobierno estatal y local- cancelaron e inhabilitaron su experiencia y su trabajo en lugar de fortalecerlo.

En resumen, para los pobladores del ejido de San Ignacio de Arareco, la década de los noventa del siglo pasado marcaría una nueva etapa en este proceso de cambio. Con la implementación del pac en 1995, el Estado mexicano integraría y simultáneamente cancelaría catorce años de trabajo en salud pública de este grupo de mujeres rarámuri. De igual forma, con la constitución del complejo ecoturístico, en 1991, el grupo de hombres dedicados a la promoción de salud para el cuidado dental llega también a su fin; ya que en conjunto dedicarían su esfuerzo a la defensa del territorio y posteriormente a la administración de este proyecto (Servín Herrera, 2008, p. 134). Por este motivo, la colaboración entre hombres y mujeres se reformulará en la ejecución del proyecto de desarrollo turístico, también promovido por el gobierno del estado de Chihuahua.

Una expresión de esto fue la primera mesa directiva del complejo ecoturístico, conformado en Asamblea Ejidal por un presidente, un secretario, un tesorero y dos mujeres promotoras de salud y de educación. Pese al equilibrio logrado, el primer desencuentro radicó en la forma de distribución de las ganancias; ya que las promotoras de salud pidieron que las utilidades se repartieran en especie y no en dinero en efectivo pues: "se pensó que los señores iban a gastarlo en la tomadera [bebidas alcohólicas]. Entonces las mujeres promotoras decidimos que se diera en comida. Pero pos ya después al otro año la gente no quiso comida y querían mejor el dinero. Y pos así lo decidieron entre todos." ${ }^{11}$

A esta primera discrepancia se sumarían una serie de conflictos por la gestión de las tiendas de artesanías y de la escuela de Gonogochi en los que participarían integrantes de las ONG de la Iglesia católica, del gobierno del estado y los rarámuri del ejido de San Ignacio de Arareco. Para las integrantes de Kari Igomari Niwara este proceso fortalecería una imagen negativa de las ex promotoras de salud. Por ello, sugiero que a manera de respuesta, algunas de estas mujeres intensificaron su articulación con algunas ONG como Alcadeco, A. C., y Semillas, A. C.; lo cual se manifestaría en la variación de las versiones sobre la constitución de esta Sociedad de Solidaridad Social que presenté en la primera parte de este artículo. En este proceso, tomando

${ }^{31}$ Ramírez, C. (julio de 2004). Entrevista a Crucita Ramírez/Entrevistadora Servín Herrera, Rukusárare, Chihuahua. En Servín Herrera (2008, pp. 145-146). 
como fundamento la posibilidad de cambiar las relaciones que "no cuidaban colectivamente" el camino de todos, las rarámuri de San Ignacio de Arareco destacarían y robustecerían el papel de las mujeres como agentes de cambio, reubicando la violencia como el motor para la transformación y reconociendo su trabajo de organización desde 1981; tal como se expresa en la narración de la conformación de la Sociedad de Solidaridad Social ofrecida por una mujer rarámuri para el Boletín Informativo de Semillas, A. C. de diciembre de 2013: "los hombres no se daban cuenta de que dábamos talleres a otras mujeres, y decían [que] no nos dejaran andar sueltas, que debíamos andar en la casa" o bien que "sólo en bola (en grupo) lo podemos lograr [...] antes, nos daba miedo venir y todavía había mujeres que se iban porque decían vámonos que si no, nos van a zumbar (golpear)" (Kari Igomari Niwara, 2013).

\section{PALABRAS FINALES}

En este texto expuse algunas de las narrativas divergentes que han constituido la historia reciente del ejido de San Ignacio de Arareco en la Sierra Tarahumara. El objetivo general fue describir la constitución de Kari Igomari Niwara desde la perspectiva de las mujeres rarámuri, documentada sobre el terreno en el presente y en la cual ellas son agentes de cambio, con la finalidad de que esta versión restituyera parte de su complejidad a la historia de la región.

Metodológicamente mostré la operatividad de la historización de la etnografía, así como la utilidad de someter otros documentos producidos durante el siglo xx y el xxi a una crítica de fuentes interdisciplinaria para elaborar una historia capaz de dialogar y reconocer en su complejidad la perspectiva de los rarámuri. Cabe destacar que sólo a través de trazar rutas indagatorias desde la historia reciente a la antropología y viceversa fue posible narrar una de las versiones femeninas e indígenas para dar cuenta de su vinculación con el desarrollo institucional del Estado mexicano, mostrando en consecuencia una manera de cómo ambas disciplinas podrían enriquecerse. Analíticamente señalé cómo la narrativa explícita sobre la violencia familiar y de género, en tanto motor de cambio social, se consolidó e intensificó durante la primera década del siglo xxI. Sin embargo, su fundamento fue la experiencia rarámuri que antecedió a la intervención de las ONG; y posiblemente las premisas de la sociabilidad rarámuri. Por tanto, sugerí que la articulación 
de los rarámuri con estas organizaciones podría ser una consecuencia y no una causa del cambio sucedido durante las últimas décadas del siglo xx y las primeras del XXI, tal como lo describen las versiones de estas mujeres; o en todo caso una convergencia cocreativa simétrica.

Además, desde la narrativa de las rarámuri y tomando como ejemplo la gestión de la salud pública, expliqué cómo sus relaciones con la Iglesia católica y el Estado mexicano se transformaron en los últimos 30 años. Si durante casi todo el siglo xx estas instituciones colaboraron para atender la salud y la educación en gran parte de la Sierra Tarahumara (Sariego Rodríguez, 2015, pp. 287-302), a partir de 1981 los rarámuri se vincularon con diversas ONG para promover proyectos de autogestión en estos dos ámbitos. En este último periodo, la presencia del Estado mexicano en la salud parecía nula en la región de San Ignacio de Arareco puesto que no se contaban con registros oficiales sobre desnutrición y mortalidad infantil. Sumado a esto, la clínica más cercana que atendía gratuitamente a los rarámuri, en el pueblo de Creel, fue fundada en 1979 por Luis G. Verplancken J. S. (Velasco Rivero, 2015, pp. 6-24). En este contexto, podría sugerir que fueron los rarámuri quienes aprovecharon la presencia de las ONG para ejecutar un proyecto de autogestión sobre la salud comunitaria y no exclusivamente, como afirman los documentos revisados, que fueron las ONG quienes lo promoverían. En otras palabras, y como se observó al contraponer distintas versiones, los intereses en juego nunca fueron unilaterales pese a que llegaron a convergir bajo la figura de proyectos de desarrollo compartidos o espacios de disputa, tal como el caso descrito en este artículo lo ejemplifica. ${ }^{32}$

Sumado a esto, al destacar los intereses y la agencia de las rarámuri cuestioné los efectos progresivos de las narrativas bajo los cuales el desarrollo y la autogestión han sido presentados como el producto de procesos evolutivos en el tiempo. Como señaló León Portilla (2016, pp. 67-69), las formas de gobierno amerindias que serían reconocidas en las Leyes de Indias fue-

${ }^{32}$ El vínculo entre la Iglesia católica, las políticas de la federación, los gobiernos locales y estatales y los rarámuri durante los siglos xx y xxi requiere una revisión regional y local. Por ejemplo, mientras que en la región de San Ignacio de Arareco, el PAC se implementó hasta 1996; entre 1965 y 1966 Cusárare, ubicado aproximadamente a $40 \mathrm{~km}$, se reporta como una de las escuelas atendidas por el Centro Coordinador Indigenista de la Tarahumara (ссіт); posiblemente como un indicador de la disputa por controlar "el problema indígena" entre la federación y la Iglesia católica durante esa época. Informe anual. Sección de Educación. cсіт. 1965-1966. En Cсіт, leg. 151, exp. 2. Citado en Sariego Rodríguez (2015, p. 292). 
ron radicalmente excluidas del contexto jurídico del México independiente del siglo xIx y de sus posteriores marcos institucionales en el siglo xx. En consonancia, como destacó Sariego Rodríguez (2015), la autonomía indígena ha sido incompatible con el proceso de aculturación y fue convertido en un proyecto involutivo bajo los términos de la integración nacional, es decir, consecuente con la idea nacionalista y de nación derivada de la revolución $\mathrm{y}$ acorde con los postulados integracionistas, el indigenismo del siglo $\mathrm{xx}$ ha negado toda viabilidad a cualquier proyecto de autonomía indígena (p. 33). Aquello que deseo resaltar es que el reconocimiento de la autonomía y de la autogestión de algunos colectivos amerindios no es un fenómeno exclusivo de los siglos xx y xxi. Como demostré a lo largo de este texto, desde la perspectiva de las mujeres rarámuri la autogestión generada junto con las ONG es producto de una experiencia propia que podría preceder a su vinculación, o dicho en otros términos, podría ser previo a la intervención institucional y a la promoción del desarrollo que he descrito.

Finalmente, si es en el presente y sobre el terreno donde surgen las preguntas que hacen necesario nuestro viaje en el tiempo, entonces es preciso sumar en nuestros análisis las versiones de la historia narradas por las mujeres en América Latina, ya que en muchos de los casos donde el Estado-nación se articula con la explotación de recursos naturales y humanos son ellas quienes dirigen los movimientos y construyen alternativas. ${ }^{33}$ Considero que una de las aportaciones para nuestra tarea actual, además de ampliar la comprensión de los lazos tejidos entre el Estado-nación, las iglesias y las oNG, es que estas otras historias podrían hacer parte de las reflexiones sobre los feminismos no occidentales de América Latina (Gargallo Celentani, 2014); los cuales, al revertirlos hacia nosotros, nos permitirían preguntarnos sobre nuestra propia historia reciente.

${ }^{33}$ Esto se expresa en el mapa creado por mujeres latinoamericanas Tejiendo Territorios (Enviromental Justice Atlas, 2017). Elaborado en marzo de 2017 por la Red Latinoamericana de Mujeres defensoras de los derechos sociales y ambientales, CENSAT Agua Viva/Amigos de la Tierra Colombia y ACKnowl-Ej (Academic-Activist Co-Production of Knowledge for Environmental Justice). Este trabajo de mapeo visibiliza 21 de los conflictos ambientales en los que las mujeres desempeñan un papel decisivo en la defensa del territorio. Se concentra exclusivamente en conflictos mineros por ahora, en México, Guatemala, El Salvador, Honduras, Colombia, Ecuador, Perú, Bolivia y Uruguay. 


\section{LISTA DE REFERENCIAS}

Anderson, A. E. (1994). Ethnic tourism in the Sierra Tarahumara: A comparison of two rarámuri ejidos. (Master's Thesis). The University of Texas, Austin.

Broda, J. (1995). La historia y la etnografía. Cambio y continuidades culturales en las sociedades indígenas de México. En Reflexiones sobre el oficio del historiador (pp. 11-36). México: Instituto de Investigaciones Históricas-Universidad Nacional Autónoma de México.

Broda, J. (2003). La ritualidad mesoamericana y los procesos de sincretismo y reelaboración simbólica después de la conquista. GRAFFYLIA, Revista de la Facultad de Filosofía y Letras, 2, 14-27. Recuperado de https://dialnet.unirioja.es/servlet/ articulo? codigo $=2150708$

Enviromental Justice Atlas (2017). Mapa creado por mujeres latinoamericanas Tejiendo Territorios. Recuperado de http://ejatlas.org/featured/mujeres

Farías Martínez, A. y Aranda Gutiérrez, H. (2008). Estudio básico de comunidad: ejido San Ignacio de Arareco. México: Facultad de Zootecnía y Ecología-Universidad Autónoma de Chihuahua. Recuperado de http://www.fz.uach.mx/data/files/ Estudio\%20Basico\%20San\%20Ignacio\%20de\%20Arareco.pdf

Faubion, J. D. (2016). On the anthropology of the contemporary. Adressing concepts, designs, and practices. HAU, Journal of Ethnographic Theory, 6(1), 371-402. DOI: 10.14318/hau6.1.020

Fondo Semillas (7 de mayo de 2010). Kari Igomari Niwara. Recuperado de https:// www.youtube.com/watch?v=enrL_Fu6Yz0

Frade Rubio, L. (19 de septiembre de 2012). Ficha de Registro Kari Igomari Niwara. Red de Innovaciones Educativas para América Latina y el Caribe (Innovemos). Organización de las Naciones Unidas para la Educación, la Ciencia y la Cultura. Recuperado de : https://web.archive.org/web/20120919052319/http://www.redinnovemos.org/content/view/252/113/lang,sp/ Link original: http://www.redinnovemos.org/content/view/252/40/lang,sp/

Gargallo Celentani, F. (2014). Feminismos desde Abya Yala. Ideas y proposiciones de las mujeres de 607 pueblos en nuestra América. México: Editorial Corte y Confección. Recuperado de: https://francescagargallo.files.wordpress.com/2014/01/francesca-gargallo-feminismos-desde-abya-yala-ene20141.pdf

Hobsbawm, E. J. (2007). Historia social. En G. Vera Hernández, J. R. Pantoja Reyez, M. X. Domínguez Pérez y O. Arreola Rosas (coords.), Los historiadores y la historia para el siglo XXI: homenaje a Eric J. Hobsbawm. 25 años de la licenciatura de Historia. 
México: Escuela Nacional de Antropología e Historia/Consejo Nacional para la Cultura y las Artes.

Ingold, T. (ed) (1996). Key debates in anthropology. Londres y Nueva York: Routledge. Instituto Nacional de Lenguas Indígenas (INALI) (2010). Indicadores básicos de la agrupación tarahumara, 2010. Recuperado de http://site.inali.gob.mx/Micrositios/estadistica_basica/estadisticas2010/pdf/agrupaciones/tarahumara.pdf

Kari Igomari Niwara, La casa es de las mujeres (diciembre de 2013). Semillas, IX(78) Recuperado de https://web.archive.org/web/20140103022438/http://semillas.org. $\mathrm{mx} /$ semillero/dic13/interior.html

Levin Rojo, D. A. (2016). ¿Etnografía o historia para el presente? Cómo estudiar las comunidades hispano-mexicanas en Nuevo México. Habitus, 14(2), 143-155. DoI: 10.18224/hab.v14.2.2016.143-155

León Portilla, M. (2016). México y América Latina. De su historia, penurias y esperanzas. México: El Colegio Nacional.

López Caballero, P. (2017). Indígenas de la nación. Etnografía histórica de la alteridad en México (Milpa Alta, siglos XVII-XXI): México: Fondo de Cultura Económica.

Martínez González, R. (2013). Cuiripu: cuerpo y persona entre los antiguos p'urhépecha de Michoacán. México: Instituto de Investigaciones Históricas-Universidad Nacional Autónoma de México.

Martínez, I. y Fujigaki Lares, A. (2014). Un niño rarámuri y su camión. Juguete tradicional. Forma y Fantasía. Artes de México, 113, 45-51.

Martínez Ramírez, M. I. (2012). Alteridad, multiplicidad y reversibilidad en clave rarámuri. Crónica de un viaje por la antropología del otro. (Tesis de doctorado). Universidad Nacional Autónoma de México, México.

Martínez Ramírez, M. I. (2017). "Nadie está aislado de nadie”. Descripciones prescriptivas de los Otros en la Sierra Tarahumara. Estudios de Historia Moderna y Contemporánea de México, 53, 38-58. DoI: 10.1016/j.ehmcm.2016.11.001

Morales Muñoz, M. V. (2014). "Aquí la mujer se siente más responsable". Género y etnicidad. Entre relaciones de complementariedad y desigualdad. (Tesis de doctorado). Centro de Investigaciones y Estudios Superiores en Antropología Social, México.

Ocampo, Manuel, S. J., (1966). Historia de la Misión de la Tarahumara (1900-1965). México: Editorial México Heroico.

Pérez Castro Vázquez, J. C. (2004). Incorporación de los hombres en procesos de educación ambiental con perspectiva de género, reto para el desarrollo sustentable. (Tesis de maestría). Universidad de Guadalajara, México. 
Salgado Estrada, F. A. (2008). San Ignacio de Arareco. Un ejido, tres pueblos. (Tesis de maestría). Escuela Nacional de Antropología e Historia, Unidad Chihuahua/Centro de Investigaciones y Estudios Superiores en Antropología Social, México.

Sariego Rodríguez, J. L. (2015). El indigenismo en la Tarahumara. Identidad, comunidad, relaciones interétnicas y desarrollo en la Sierra de Chihuahua. México: Instituto Nacional Indigenista/Consejo Nacional para la Cultura y las Artes/Instituto Nacional de Antropología e Historia.

Sariego Rodríguez, J. L. (coord.) (sin año). San Ignacio de Arareko. Guía para adentrarse a su entorno natural y al saber tarahumara. México: Escuela Nacional de Antropología e Historia, Unidad Chihuahua/Gobierno del Estado de Chihuahua.

Semillas, Sociedad Mexicana Pro Derechos de la Mujer, A. C. (2017). Recuperado de https://semillas.org.mx

Servín Herrera, A. E. L. (2008). Mujeres indígenas y desarrollo. Dos experiencias en la Sierra Tarahumara. México: Colección Escuela Nacional de Antropología e Historia-Chihuahua.

Strathern, M. (2013). Fora de contexto: as ficções persuasivas da antropologia. Brasil: Terceiro Nome.

Strathern, M. (2014). O efeito etnográfico e outros ensaios. Brasil: CosACNAIFY.

Trevizo Nevárez, J. y Abúndez Ramírez, N. (1996). San Ignacio de Arareco: una experiencia del Procede en la Sierra Tarahumara. Estudios Agrarios, 2(3), 131-137. Recuperado de http://www.pa.gob.mx/publica/cd_estudios/pdf/3.pdf

Velasco Rivero, Pedro S. J. de (2015). A Tarahumara wellness story. Oregon: Tarahumara Children's Hospital Fund. Recuperado de http://www.tchforegon.org/sites/default/ files/docs/Tarahumara\%20Wellness\%20Brochure\%20OCTOBER\%202015.pdf

\section{OTRAS FUENTES}

\section{Recursos electrónicos}

Comisión de Solidaridad y Defensa de los Derechos Humanos, A. C. (2017). Recuperado de http://www.cosyddhac.com 


\section{Bibliografía}

Hobsbawm, E. J. (2014 [1995]). Historia del siglo Xx. Historia del mundo contemporáneo. España: Crítica.

Instituto Nacional de Lenguas Indígenas (INALI) (2015). Indicadores básicos de la agrupación tarahumara, 2010. Recuperado de http://site.inali.gob.mx/Micrositios/estadistica_basica/estadisticas2015/pdf/agrupaciones/tarahumara.pdf

Martínez Juárez, V., Almanza Alcalde, H. y Urteaga Castro Pozo, A. (sin año). Diagnóstico sociocultural de diez municipios de la Sierra Tarahumara. Recuperado de http://alianzasierramadre.org/images/en/downloads/diagnostico_sociocultutal.pdf

Pimentel Kmitta, S. (2012). Elementos para uma teoria política kaiowá e guarani. (Tesis de doctorado). Universidade de São Paulo, Brasil.

Rodríguez, G. (6 de agosto de 2004). La revolución de las rarámuri. La Jornada. Recuperado de http://www.jornada.unam.mx/2004/08/06/022a2pol.php?printver=1\&fly= Sheridan, T. E. (1996). The railroad and the Tourists. En T. E. Sheridan y N. J. Parezi (eds.), Paths of life. American indians of the southwest and northern Mexico (pp. 159161). Tucson: The University of Arizona Press. 